\title{
Multiple Mind/Body Perspectives and the Out-of-Body Experience
}

\author{
F. Gordon Greene
}

\begin{abstract}
This study reviews and analyzes evidence for a rare but persistently reported facet of out-of-body experience (OBE)/near-death experience (NDE) phenomenology designated the "multiple-body/split-consciousness" effect. Those who experience this effect describe the sensation of possessing and in some instances simultaneously occupying a multiple number of "bodies" at varying locations, sometimes in conjunction with the sense of being disembodied. A variant on this experience, during which subjects seem to shift awareness alternately between two or more locations, is also treated. The thoughts of previous OBE/NDE researchers on multiple-body/split-consciousness sensations are reviewed. Nine cases illustrative of such experiences are then cited and discussed. Also mentioned are related altered states of consciousness invoked in the neurosurgeon $W$. Penfield's patients by electrode probes to the cerebral cortex during open-brain surgery. A neurological explanation for this study's case material based on an extrapolation of Penfield's findings is presented. A non-Euclidean/higherspace explanation is then proposed, derived from a multidimensional extension to mathematician B. Mandelbrot's "fractal geometry." The branch of mathematics called topology is utilized in the development of this latter theory. The article ends with a brief reference to this hypercomplex multidimensional geometry's possible import for understanding "multiple personalities" and "spirit controls."
\end{abstract}

\section{INTRODUCTION}

The sensation among out-of-body experiencers and near-death episode subjects of simultaneously possessing two or more bodies, or of simultaneously occupying two or more locations, has been reported rarely but persistently over the years by parapsychologists and neardeath researchers (e.g., Tyrrell, 1947; Muldoon and Carrington, 1951; Whiteman, 1961, 1978; Broad, 1962; Crookall, 1964a, 1964b; Green, 1968; Osis, 1978; Rogo, 1978b; Ring, 1980; Gallup, 1982). These multiple-body/location feelings have sometimes been experienced in conjunction with the sense of being disembodied. A possibly allied phenomenological sensation also sometimes chronicled in OBE/ NDE literature entails the feeling of OBE-related consciousness shifting perspective alternately between two or more locations (e.g., Green, 1968; Noyes and Kletti, 1977).1 
For the purposes of this article such "multiple simultaneous" and "multiple alternate" OBE/NDE sensations are viewed as family members in the same phenomenological constellation. Because this general effect sometimes has not been described in enough detail to determine clearly whether feelings of embodiedness or disembodiedness were present, and because a number of these cases included a combination of these feelings (e.g., at one location subjects may have felt they were inhabiting an "astral body" while simultaneously at another they may have experienced the sense of being disembodied), this general phenomenon is designated the "multiplebody/split-consciousness" effect. When treating particular cases, appropriate modifications of this terminology are used.

Before citing and commenting upon this study's nine accounts and the phenomenologically related altered states of consciousness (ASCs) elicited by neurosurgeon Wilder Penfield's (1975) electrode probes, let me review the thoughts of previous researchers relevant to this general effect.

\section{PREVIOUS COMMENTARY}

Parapsychologists J.H.M. Whiteman $(1961,1978)$, Robert Crookall (1964a, 1964b), and D. Scott Rogo (1978b) and near-death researcher Kenneth Ring (1980) are among the few investigators to have commented on multiple-body/split-consciousness cases. Parapsychologists George N.M. Tyrrell (1947), Celia Green (1968), and Karlis Osis (1978) have referred to what may be a related OBE effect, the nature of which will be discussed shortly. Alternate shifting location OBE/NDEs, though apparently experienced by a number of subjects, have yet to be discussed by researchers other than in passing.

Whiteman, who personally experienced a number of OBEs during which multiple-body sensations were present, as documented in his book The Mystical Life (1961), proposed a rather complex theory of human personality to account for these experiences. The apparent unity of physical-world, human consciousness seemed for Whiteman to be illusory. He suggested it is actually composite in nature, a composite whose varying elements are partially unmasked during OBEs. Ultimately Whiteman believed that " the real I' (individuality, soul) is found in its purity and perfection only in mystical states ..." 1978, (p. 290).

Rogo referred to multiple-body/split-consciousness sensations as "double-release" OBEs and noted: 
The consciousness is released from both the physical body and the ecsomatic body, each of which is seen from a spatially separate vantage point. Such reports are rare in out-of-body literature ... Cases in which such a distinct double-division is reported cannot easily be explained away as due to incorrect observation, expectancy, or errors of reporting. Doublerelease OBEs are so extraordinary that one wonders if they can be so readily explained on any grounds except that some sort of physical separation is really taking place between the mind, the body, and some sort of ultra-physical body (1978b, p. 49).

Although Rogo argued that the OBE theories of Crookall (1961, $1964 \mathrm{a}, 1964$ b) cannot provide researchers with a comprehensive explanation for OBEs, in the above passage the influence of Crookall's thinking is quite discernable. (For this reason we need not directly review Crookall's own thoughts on multiple-body experiences.) Rogo (1978a) did write that Crookall's theories, appropriately modified and supplemented with additional insights from other sources, however, offered a valuable conceptual framework potentially capable of explaining the OBE. Rogo conceived of multiple-body/ split-consciousness OBEs in terms of some sort of "double-division" and used various conceptual mannerisms of Crookall to interpret these experiences. However, some cases in this genre of OBE seem not to include a double but rather entail a triple division of the experient's "bodies" and/or consciousness. It is always possible to incorporate an additional body and then another into an extended version of Crookall's model. The non-Euclidean/higher-space explanation, however, need not be altered in any way nor necessarily multiply its hypothetical entities in the least to accommodate multiple-body/split-consciousness cases including any number of bodies/ locations.

Ring (1980) referred to multiple-body/split-consciousness cases as instances of "dual body perception" but did not offer a theoretical explanation to account for such phenomena.

Tyrrell (1947) and Green (1968) mentioned OBEs in which consciousness appeared to be split between the physical body and the OBE locus of perception. Of these cases Tyrrell remarked, "There is not only a separation of the self from the body but also a division occurring. in the personality itself" (p. 195). In Green's study 16 percent of the subjects experienced the sensation of dual physicalbody/OBE awareness. Summarizing the results of the American Society for Psychical Research "fly-in" screening test for out-ofbody ESP, Osis remarked, "Very few persons succeeded who felt that their consciousness was located simultaneously in both the 
physical body and my office" (1978, p. 163). Although the sensation of simultaneous physical-body/OBE awareness enters discussion in this article, this study's primary concern is with cases where experients felt themselves to be inhabiting two or more bodies and/or locations separate from and in addition to the physical body.

On this last point let me review the case material.

\section{THE CASE MATERIAL}

My first case came from the mid-twentieth-century American spiritualist Mr. Reynolds (Muldoon and Carrington, 1951). Although this experience occurred during a "dream," it possesses the foremost characteristic of the OBE, i.e., the apparent perception of the subject's physical body as if from an exterior position in space.

In attempting to reconstruct this "dream OBE," Mr. Reynolds drew the following diagram:

Figure 1
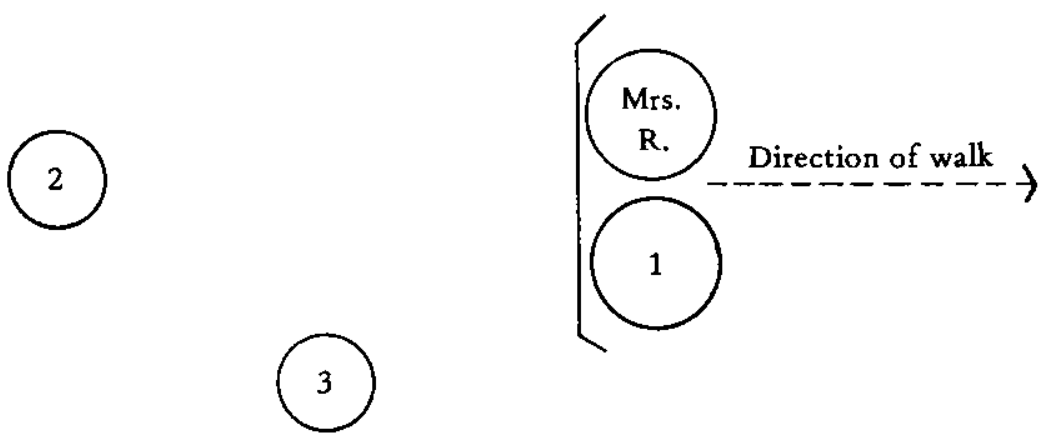

(Excerpted from Muldoon and Carrington, 1951, p. 133.)

Of his drawing Mr. Reynolds remarked:

I have indicated where I was, that is, the three different locations. At (1) I saw only Mrs. Reynolds [who had died several years previously]; she was real and I had my arm around her shoulders.

At (3) I had no sensation whatever; that was my physical self, simply being observed there from point (2). 
At both (1) and (3) I presented my everyday appearance to myself from point (2).

From point (2) Mrs. Reynolds appeared the same to me as she did at point (1). From neither point (1) nor (3) did I see myself at point (2).

$I$ afterwards came to the conclusion that my mind must have been inert at point (3), my physical body, or not there at all. That it (my mind) must have been at both point (2) and (1) at the same time, or else two minds, or else the same mind divided, or, to make it more clear, a duplicate mind, one at (2) and one at (1).

The distance between point (1) and (2) and point (2) and (3) was about fifteen feet.

It seems to me that my spirit, I will say, was at point (1), that some intermediary body of mine was at point (2) and that my physical self was at point (3).

I know it all sounds complicated, but $\mathbf{I}$ have given you a vague picture of what to me was very clear when it happened ... (p. 133).

Some may be suspicious of the above account. How reliable is the testimony of an individual many might conceive to be a naive spiritualist? When one reflects, however, upon the rarity with which multiplebody/location experiences have been reported in the literature, the prospect that Mr. Reynolds's account was somehow influenced by previous reading is greatly diminished. His was actually the earliest multiple-body account published, among the cases reviewed in this study. This fact seems to add at least some credence to Mr. Reynolds's testimony. Whatever one's feelings towards spiritualism, Mr. Reynolds's words do provide us with a classic example of the multiplebody/split-consciousness effect.

The next multiple-body case came from a personal account by Whiteman, who stated:

I became suddenly aware of a blaze of light, of spiritual quality, while apparently in a separated state [Whiteman's term for the OBE]. Because the effect was still indefinite, though vivid, I tried to increase the precision of perception by recalling the state of recollected "one pointedness" [i.e., terminology from Christian mysticism denoting a state of harmonious rapport between the personal soul and the will of God]. This did not come spontaneously, however, and the effort was followed by awareness, in a lower state, as of the separated form on the floor beside the bed, while simultaneously the consciousness appeared in part to reside in another form in the process of separating from the position in bed. Both these separated positions were surveyed (with disapproval) from a higher state (1978, p. 286).

In this account consciousness appears to have been divided simultaneously into at least two locations. The meaning of the statement 
"Both these separated positions were surveyed from a higher state" is ambiguous. Speculations concerning the nature and whereabouts of this "higher state" follow in the explanatory section.

Our next multiple-body/split-consciousness case came from Ring (1980) and concerned a suicide attempt-initiated NDE. The subject, recounting the experiences occurring apparently just after he hung himself, remarked:

I was wearing this gray suit that I bought last year [he was actually attired differently 1 and $I$ was walking away from myself hanging there. I could also see that from where I was in the suit I could see both people at the same time, more or less (p. 46).

Ring noted that the subject "not only saw himself moving through nonphysical space but [saw] his physical body as well"' (p. 46). It is possible to interpret that consciousness was reported in both the non-physical double and also at a location where both the suited double and the hanging physical body could be seen. 2 But where was the position from which he apparently saw these two scenes? Nowhere in the account is it referred to. The possible location of this "mystery position" is treated in the explanatory section.

In the following case an NDE subject, reporting on his excursion into another world, noted:

It sounds like an hallucination when I talk about it, but it clearly wasn't for me. Also people of some sort were in the midst of all this engaging in a festive party. The whole thing gave me a good feeling. I was experiencing and participating in this scene, as a part of the celebrating group, but $\mathbf{I}$ was also observing it. It was as though I was both inside of it and outside of it at the same time (Gallup, 1982, pp. 106-107).

This subject's account differs from the previous cases in that it reported what seems to be a multiple-location experience that took place in a transpersonal or "heavenly" environment rather than in the apparent general vicinity of the physical body.

The following case, combining several interesting elements I have yet to comment upon, was a personal account from Rogo:

I had been asleep but awoke with a rapid feeling of linear movement. I felt myself in both the physical and astral [bodies]. All of a sudden I felt that I had been catapulted from the physical body and had a glimpse of it. However, as odd as this may seem, I realized that my Consciousness and sight stemmed from a point not within either body. I was viewing both bodies from another side of the room. I did not feel I had any body 
at all, but could feel the movement of my "double." I began to lose consciousness and found myself in the body again (1978b, p. 50).

In Rogo's account first consciousness was reported to reside simultaneously in the physical and astral bodies. Later it was said to reside in neither of these bodies but rather in a third location across the room. This is, however, not an entirely valid analysis of the description. Rogo did report at least tactile sensations stemming from his astral body at the time vision and cognition were said to be elsewhere.

I wonder if this account demonstrates a clear-cut division of Rogo's astral sensibilities. Did he possess only astral vision and cognition at one location because his astral tactile senses apparently resided elsewhere and vice versa? This article will not answer such a question. A search for further cases of this type, however, may result in additional clues concerning their meaning.

In the following two accounts the experients observed several bodies but did so apparently from one position. The first subject remarked:

[A] lthough I was unconscious, I saw the hospital room with doctors surrounding Dr. G. who was at my bedside, bending over me, listening to my heartbeats with a stethoscope, her fingers on my wrist taking my pulse. At the same time I saw, over my body lying on the bed, another body of me suspended in midair in the exact position, hanging from the ceiling by what seemed to be a cord attached to my navel. I seemed to be an observer but from where, I cannot say. All I know is that I saw two bodies of myself. I watched this sight for some time (Rogo, 1978b, p. 49).

The information necessary to be certain if any astral sensibilities resided in the subject's astral body is lacking in this case. No such sensations were mentioned, and sight and cognition reportedly lay at a location the subject could not identify. The possible nature and whereabouts of this other location are discussed in the explanatory section.

The second subject remarked:

I was in bed running a temperature of 104 degrees. Suddenly I found that I could see my physical body lying in bed and another body outside the bed, also in a recumbent position about a foot higher than the physical body. The second body was a very scintillating blue, pulsating with light. But it seemed to me that "I" was still in another body looking at these other two, although I was completely unconscious of any form for the third body. It seemed that that which was the "I" saw both the physical body and the bright body (Crookall, 1964a, P. 75). 
In this case the subject reported that he perceived multiple bodies. He seems to have viewed his physical and astral bodies from a third body. Of this possible third body he remarked that "I was completely unconscious of any form [for it]." Speculations concerning his inability to comprehend this third body are covered in the explanatory section.

So far I have reviewed multiple-body/split-consciousness cases where the subjects sensed they simultaneously inhabited multiple bodies and/or locations, or observed multiple bodies but did so apparently from a single position. The next case involves an OBE subject who apparently has experienced a number of out-of-body states. He could not decide when reflecting upon his OBEs if he experienced the sense of being located in several places all at once, or rather consecutively, as his consciousness shifted among different positions. In describing his OBEs, the subject said his consciousness sometimes "appears to be split in two - or occasionally even three separate places - not necessarily simultaneously, but fluctuating between the locations with no interval in time ..." (Green, 1973, p. 31).3

Another shifting-perspective altered state was associated with an NDE panoramic memory vision (Noyes and Kletti, 1977). For the present purposes I quote only a small portion of this classic life review. The experience began in the back of an ambulance while the subject was riding to a hospital after a serious automobile accident. He later wrote:

1 was drifting in and out of this cloud. As I would drift out I would be very sharp as to what was going on but as I drifted back down into it thousands of things started - my mind was going rampant. It was about everything that happened, like things I had regretted and things I had been most happy at. . . It's hard to put into words the thoughts I had. The thought I remember most was that year I was on the basketball team. I canned a thirty-five-footer at the buzzer. I went through it, it happened, I remembered what it was like... When I threw that basketball shot I could see myself going up and doing it. At the time it was like I was there. It was as if I saw it happening through my own eyes. Now I pictured it in the third person; then I experienced it in the first (PP. 186-187).

In this last case the subject also seems unclear if his multiplelocation experience occurred simultaneously or alternately. In any event this account provides what may be an excellent source for additional multiple-body/split-consciousness experiences, i.e., personal panoramic memory accounts.

This concludes the discussion of the OBE/NDE case material. 


\section{PENFIELD AND THE "DOUBLING OF AWARENESS"}

Certain discoveries by Wilder Penfield bear significantly on this study's themes. In his book The Mystery of the Mind (1975), Penfield discussed his classic open-brain-surgery research, during which he probed with electrodes the cerebral cortexes of his patients.

Because of the potential relevance Penfield's research and observations have for this study, I quote at some length his comments on the "doubling of awareness":

Consider the point of view of the patient when the surgeon's electrode, placed on the interpretive cortex, summons the replay of past experience. The stream of consciousness is suddenly doubled for him. He is aware of what is going on in the operating room as well as the "flashback" from the past. He can discuss with the surgeon the meaning of both streams.

The patient's mind, which is considering the situation in such an aloof and critical manner, can only be something quite apart from neuronal reflex action. It is noteworthy that two streams of consciousness are flowing, the one driven by input from environment, the other by an electrode delivering sixty pulses per second to the cortex. The fact that there should be no confusion in the conscious state suggests that, although the content of consciousness depends in large measure on neuronal activity, awareness itself does not.

A young South African patient lying on the operating table exclaimed, when he realized what was happening, that it was astonishing to realize that he was laughing with his cousins on a farm in South Africa, while he was so fully conscious of being in the operating room in Montreal. This illustrates what I mean. The mind of the patient was as independent of the reflex action as was the mind of the surgeon who listened and strove to understand, thus my argument favors independence of mind-action (p. 55).

A qualified scientist or philosopher aware of Penfield's findings but not sharing his interpretation could conceivably construct a plausible "neurological" counter-hypothesis to the present nonEuclidean/higher-space explanation. Such a theory would probably hinge on the proposition that some sort of unusual neuronal activity creates the multiple-body/split-consciousness sensation. In that scenario the subject's memory would somehow be drawn upon for the construction and content of the multiple-body/location experience. However, such an explanation, I would argue, lacks the wider range of the present theory in explaining diverse additional aspects of OBE-related, altered-state phenomenology (e.g., see Greene, $1980,1983)$.

Penfield's findings at least demonstrated that human consciousness is capable of simultaneously experiencing, with ludicity, two streams of awareness. Thus there is strong evidence confirming the existence 
of this general intellectual capacity from a source additional to retrospective OBE/NDE testimony. 4

\section{A NON-EUCLIDEAN/HIGHER-SPACE INTERPRETATION}

Before entering into this study's primary concern, i.e., an explanation for multiple-body/split-consciousness experiences, it should be noted that this presentation is only part of a larger theory. The larger theory is designed to account for numerous other aspects of OBE/NDE phenomenology as well as for the paranormal in general. To appreciate certain ramifications of the material covered herein, it is first necessary to discuss briefly the overall theory.

I begin with a review of two fundamental postulates of the threedimensional Euclidean world-view, a perspective that serves as the sensory/motor road map for waking-level physical reality. Space, according to this conception, is isotropic and homogeneous. That is, space is the same in all directions and the same throughout the physical universe.

Figure 2 provides us with a two-dimensional representation of this three-dimensional Euclidean construct for space. The lettered points represent randomly distributed positions inside this flat or zero-curvature space.

Figure 2

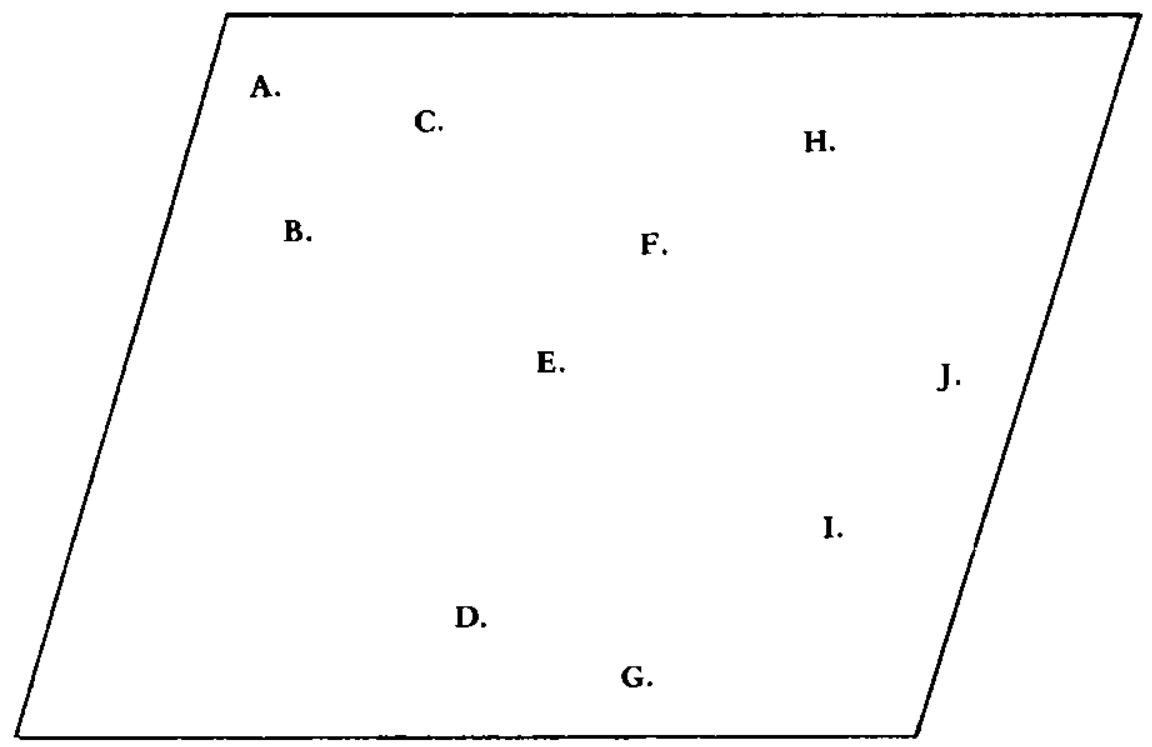


With the rise of modern scientific conceptions of the universe, this three-dimensional Euclidean construct was displaced from its exclusive status to its present position as one possible condition among a number of non-Euclidean possibilities for the underlying constitution of space.

Although the three-dimensional Euclidean world-view is still recognized as necessary for the description of human waking-level sensory/motor reality, discoveries in nineteenth- and twentiethcentury physics seem to be best explained in terms of non-Euclidean space constructs. Einstein's general theory of relativity serves as the primary example of this development. It is based on non-Euclidean conceptions of space and space curvature, which have been described in detail elsewhere (Clifford, 1955; Poincare, 1952; Nagel, 1979; Robertson, 1979; Rosen, 1974, 1977, 1983; Davies, 1980; and Rucker, 1977, 1982).

Until recently, most attempts to match non-Euclidean geometrical principles with the workings of the physical universe have relied on the ideal non-Euclidean spaces of even positive and even negative curvature. A new theory of space, however, based on the study of irregular or uneven curvature, has been proposed by the mathematician Benoit Mandelbrot (1976, 1982). Christened "fractal geometry" by Mandelbrot, this new theory has already proven its usefulness in the modeling of irregular features in the earth's cloud formations, in the study of planetary land configurations, and in the investigation of galaxy distribution (see especially Gregory and Thompson, 1982, for this application of fractal geometry).

The speculations about the paranormal by Steven Rosen (1983) on the structure of space seem to parallel in certain respects Mandelbrot's conceptions. Rosen's ideas certainly deserve scrutiny in light of the present non-Euclidean/higher-space model.

The present exposition may be viewed as a multidimensional extension of fractal geometry. Rather than examining irregular curvature "inside" the three-dimensional universe, this theory regards our three-dimensional space as radically curved in an irregular, hypercomplex fashion within a higher dimension of space.

Figure 3 represents the topology of space proposed by this model, i.e., a random, hypercomplex folding of three-dimensional space through a fourth dimension.

In this and succeeding figures all lettered points are visually represented as lying on the outer surface of the fold. However, in actual folds after which this depiction is modeled, the majority of these points would be distributed through the inner recesses of the 
Figure 3

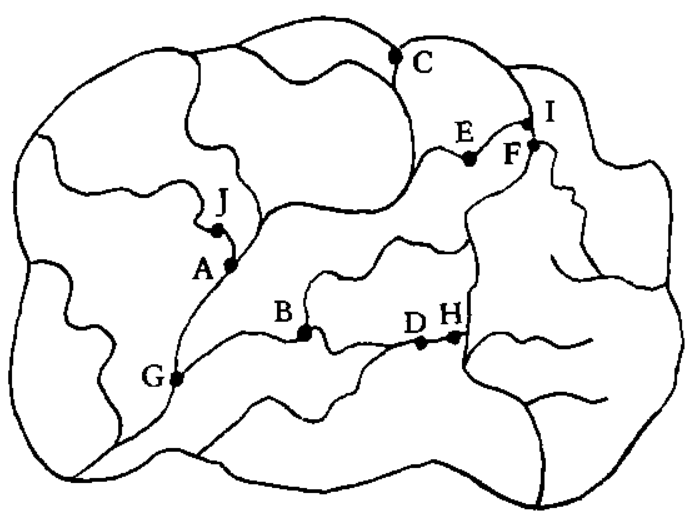

fold arid thus out of sight from any one exterior position. This design is adopted for heuristic reasons, to help readers more directly appreciate point-to-point relationships in the system. This slight deviation in no way alters the theoretical consistency of the model.

This theory suggests that three-dimensional space, conceived by our senses to develop evenly in a straight line, actually extends randomly at irregular intervals through a higher space. This is true, that is, when three-dimensional space is perceived from the outside or from a hyperspatial point of view.

If our physical universe twists in a random, hypercomplex fashion through a four-dimensional space, why is this curvature invisible to our physical senses? Actually, space-curvature invisibility follows naturally from one premise. If we assume that our three-dimensional space is embedded within rather than situated on the surface of a fourth dimension, it logically follows that this curvature is impossible to perceive.

The nineteenth-century scientist Herman von Helmholtz (1956) discussed certain logical reasons for space-curvature invisibility. And the hyperspace theorist Claude Bragdon (1972) wrote nontechnically on space-curvature invisibility.

\section{FOLDS THROUGH HYPERSPACE AND THE MULTIPLE- BODY/SPLIT-CONSCIOUSNESS EFFECT}

How does this theory explain multiple-body/split-consciousness 
experiences? First we must examine a local region of our irregularly curved, hypercomplex topology.

I select the shaded area "G."

Figure 4

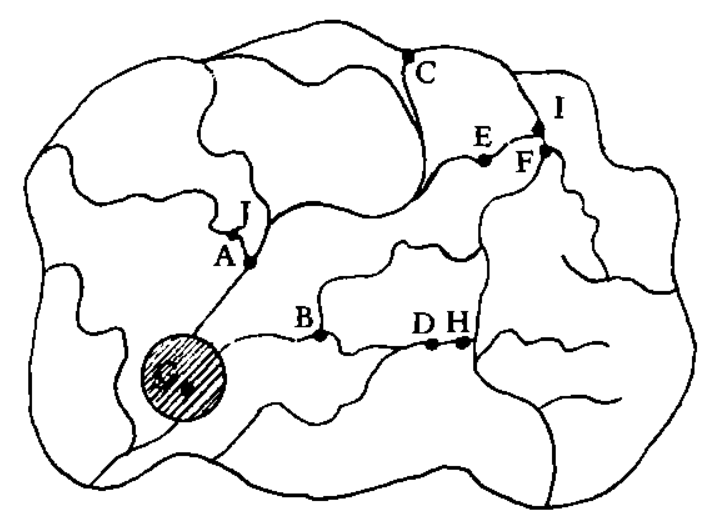

Enlarging this local fold region, we see the following image:

Figure 5

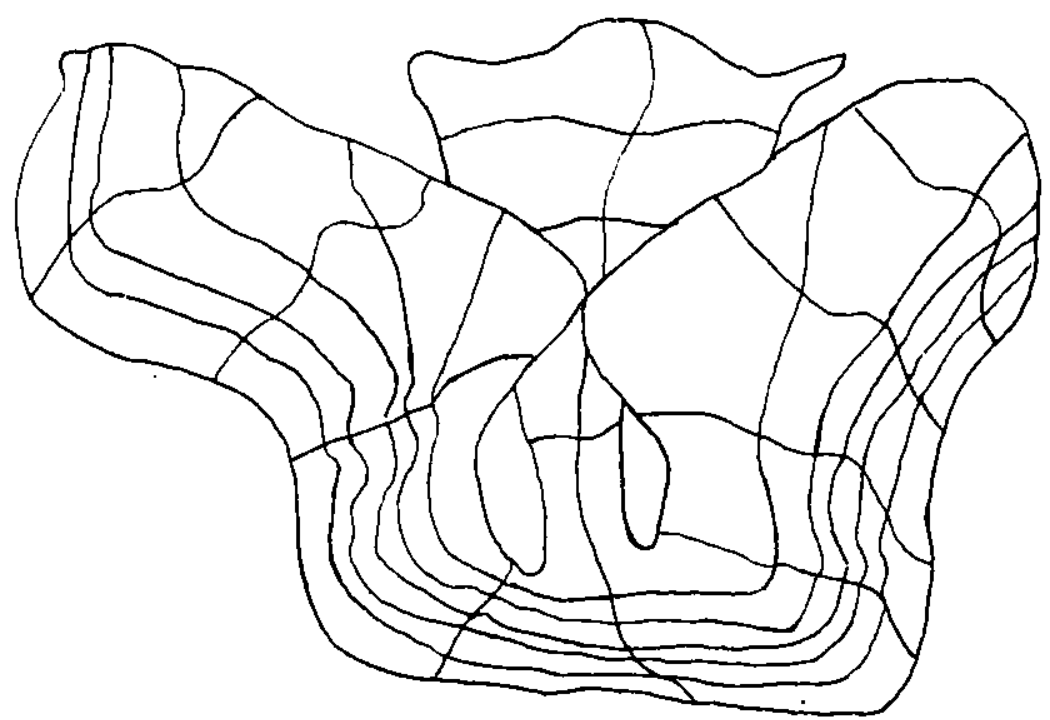


Elsewhere (1983) I used another local fold region to account for three general characteristics of OBE/NDE phenomenology: 1) spherical/circular visual and bodily sensations; 2 ) visual and bodily space distortions; and 3) the sensation of seeing around corners or of seeing simultaneously all sides of three-dimensional objects.

The present task is to demonstrate this fold's ability to explain multiple-body/split-consciousness experiences. To begin I return to Mr. Reynolds's diagram. It is necessary to reverse the positions in this drawing for reasons that should become obvious.

Figure 6

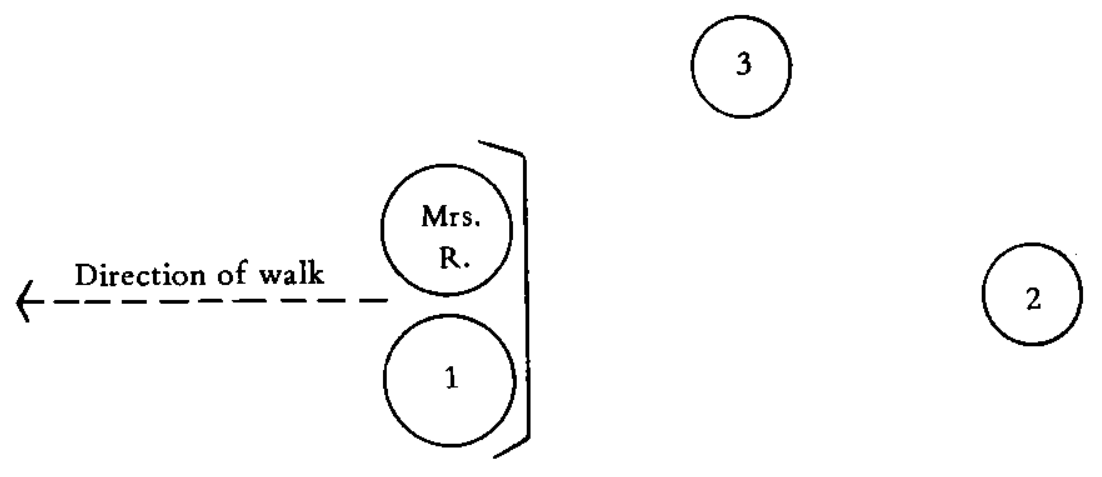

Next a grid is superimposed:

(See page 53 for Figure 7)

Finally, I use the theory's invisible curves to fold Mr. Reynolds's sketch through a higher space. We accept for the moment the truthfulness of Mr. Reynolds's report and demonstrate how this bedroom dream scene could be twisted through a higher space to account for his sense of being located simultaneously at several positions. 
Figure 7

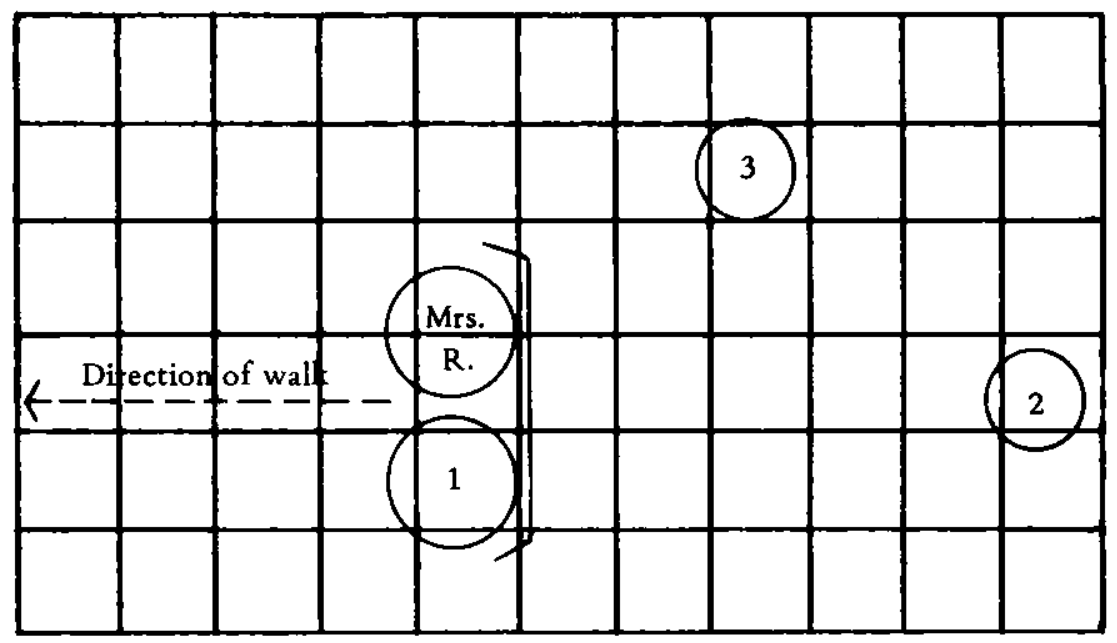

Figure 8

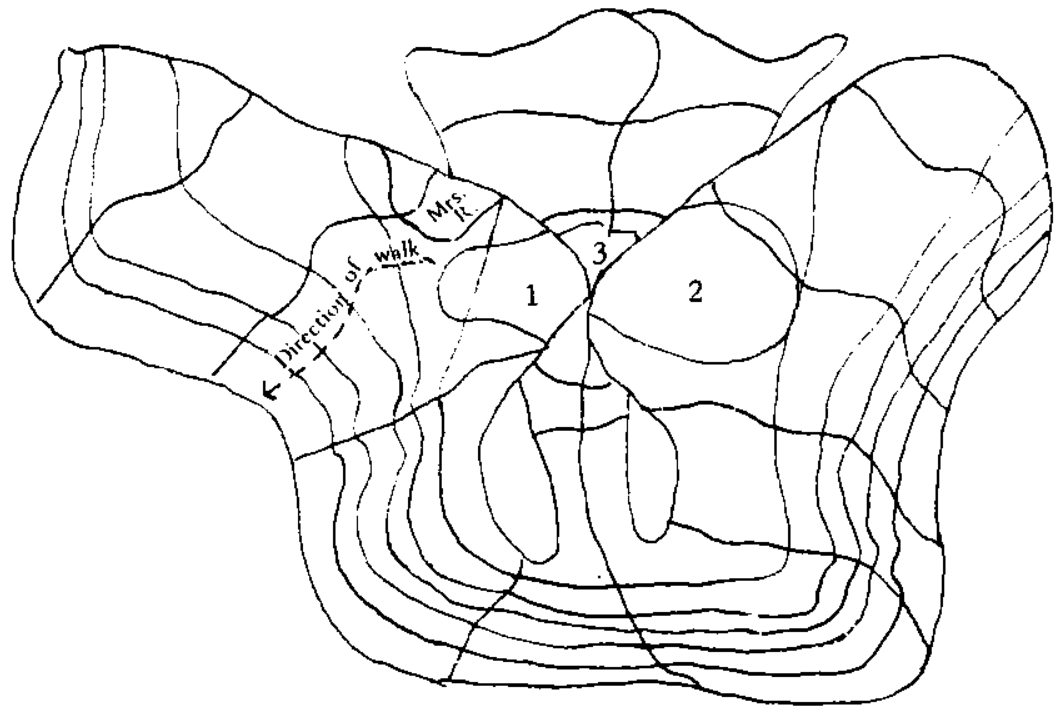


The preceding diagram provides us with a conception of how this model accounts for multiple-body/split-consciousness experiences. According to this explanation, such experiences occur when $\mathrm{OBE} / \mathrm{NDE}$ percipients move into positions in four-dimensional space where several local regions of three-dimensional space curve together, that is, connect in hyperspace. As long as OBE/NDE subjects stay in these four-dimensional folds, the multiple-body effect persists. The number of bodies and/or locations simultaneously experienced is determined by the number of three-dimensional localities connected at that particular four-dimensional location.

To explain the walk by Mr. and Mrs. Reynolds, I must extend the model one dimension further. This can be done by imagining this extra dimension randomly fluctuating throughout the convoluted threedimensional field. This fluctuation shifts the three-dimensional areas touching through hyperspace at the four-dimensional level. As long as experients move into four-dimensional positions where local fold connections exist, multiple-body/location experiences arise.

"Alternate shifting location" experiences may be explained as instances of five-dimensional fold movement, that is, as the result of the folding and unfolding of a set of three-dimensional locations.

\section{MYSTERY POSITIONS AND THE HYPERSPACE CENSOR}

One feature common to a number of this study's cases concerns the state of consciousness participating in multiple-body/split-consciousness experiences.

In Whiteman's (1978) description we heard of a "higher state" from which observation was directed to a lower level of consciousness split into bodies/locations. In the suicide attempter's account from Ring's (1980) study, an invisible third position is necessary in order to make sense of the subject's words. In the case cited originally by Rogo (1978b), the subject viewed his physical and astral bodies from a third location that could not be specified. In Rogo's (1978b) personal account, consciousness in a disembodied condition was said to view his physical and astral bodies from the other side of the room. In the case from Crookall (1964a) the subject viewed his physical and astral bodies from a third body although he was unaware of any form for this third body.

In the following discussion I propose an explanation tying these mystery-position descriptions together. Rogo's personal account in which the location of disembodied consciousness was given, and the Crookall case in which the subject inhabited a mystery form, fit into 
this overall scheme in a slightly different fashion than the other cases and are discussed last.

I now propose that the "higher state" in Whiteman's account be identified with a hyperspatial level of consciousness. Perhaps I could call it a "four-dimensional observer," to borrow a term from the hyperspace theorist John W. Dunne (1927). The disapproval attributed to this higher state resulted, I conjecture, from its inability to raise Whiteman's consciousness into a higher-dimensional perspective that could accommodate the fractured visual/tactile content of his OBE.

This proposition becomes more intelligible when we consider the hypothetical case of a point-like being whose world consists of a line. Transported onto a two-dimensional plane, this being would be faced, when looking back at its former world, with the problem of how to comprehend the higher-dimensional presentation. This being's history inculcates into its mind the notion that spatial objects are point-like. When viewing the world of the line from the outside, what does it see? Geometrically, a line is created by the continuous generation of points. An infinity of points laid side by side constitutes the line. Thus we have two languages with which to describe the nature of the line, a lower, multiple-point language and a higher, single-line language.

Perhaps in Whiteman's case, as well as in all other instances of multiple-body/split-consciousness experience, the mind fractures higherdimensional perceptions into lower-dimensional equivalents. This proposition provides us with an alternate (though certainly not mutually exclusive) higher-space explanation to the fold theory already espoused.

John White developed a theme compatible with this alternate hypothesis when he noted:

Four-dimensional vision is only an intermediate stage in the process of "clearing the doors of perception" en route to the higher perceptions of mystical vision, in which everything is seen from an infinity of points simultaneously. Or to put it another way, the single-point observer seeing in three dimensions is multiplied infinitely to become an infinite observer seeing all points simultaneously, so that the seer and seen become one process of seeing, without subject/object division (personal correspondence, 1981).

Much of what White conjectured flies far above our present concerns and will not be commented upon. His notions of four-dimensional vision as an intermediate stage to enlightenment and of multiplying 
via excursions into hyperspace the number of one's observer-selves are, however, fascinating speculations in light of this study's themes.

Hypothetically, the geometrical principles and topology in use allow for the participation of numerous additional observer selves. The above propositions raise the question as to why all the multiplebody/split-consciousness experiences reviewed in this study involve only two or three body/location perspectives.

A possible explanation is provided by the following insight. To envision a three-dimensional object in a way that is in some sense equivalent to a four-dimensional perspective, no more than a few appropriately placed three-dimensional observers are required. That is, only two three-dimensional observers appropriately positioned are necessary to see all six sides of a cube whose entire surface area can be seen from a single position in four-dimensional space.

With the above in mind I speculate that all multiple-body observers except the few required for simple four-dimensional visual perceptions usually remain unrecognized in the memories of OBE/NDE subjects. These additional observers multiply the complexity of perceptions already too complex to be integrated by waking-level consciousness used to three dimensions. Thus I introduce the notion that a three-dimensional "hyperspace censor" influences memory of OBEs and NDEs (see Greene, 1983, for additional speculations concerning this hypothetical entity).

Turning now to Ring's (1980) subject, I suggest that the proposed invisible position actually lay within four-dimensional space. It was not directly referred to by the subject because the three-dimensional censor could not identify this location inside three-dimensional space. The account drawn from Rogo (1978b) in which the subject stated that he couldn't say from where he viewed his physical and astral bodies may also demonstrate a four-dimensional location, invisible to the censor distorting the subject's memory of the experience.

As for Rogo's (1978b) personal account, I suggest that his sense of being disembodied resulted not from any lack of a body where his visual and cognitive faculties seemed to be located, but rather because his observing self was not really there. I propose that the across-theroom location in Rogo's mind actually represented a remnant memory of a four-dimensional perception. That is, from the fourth dimension all the surface features of every three-dimensional object in the room could be seen simultaneously. However, the three-dimensional censor blocked out practically the entire four-dimensional perception. All that survived in Rogo's memory, the displacement of the higherdimensional perception into "three-dimensional reality," was recog- 
nition of the scene from the widest possible three-dimensional view. That was where the most of the room's three-dimensional surfaces could be seen from one position in three-dimensional space. 5

Though not enough information is present to make this a convincing argument in Rogo's case, the censor concept seems supported by ample evidence from other sources. The hyperspace censor appears to account especially well for the unusual percentage of OBE perceptions that are said to originate from corner-ceiling positions in rooms and high-in-the-sky positions for outside OBEs. This question of the enigmatic elevated positions of OBE perspectives was recently addressed by V. Krishnan (1982) in a thought-provoking and insightful article. The present explanation offers, I suggest, a reasonable explanation for the propensity among OBE/NDE subjects to view the threedimensional scenes of their physical bodies as if from above. The case from Crookall (1964a), in which the subject believed he inhabited a body whose form he was "completely unconscious" of, seems to be phenomenologically akin to Rogo's (1978b) experience. Rogo remembered no body at all, Crookall's subject a body of unknown composition. Perhaps in that subject's inability to describe the nature of the proposed form we witness the operation of the conjectured three-dimensional hyperspace censor.

\section{CONCLUSION}

In this article I have focused attention on a rarely reported yet provocative facet of OBE/NDE phenomenology: multiple-body/splitconsciousness experiences. Although such accounts are difficult to find, the fact that they have been reported persistently over the years by independent researchers suggests that they constitute an authentic aspect of OBE/NDE phenomenology.

Appraising such experiences within the context of the present theory may illuminate diverse mental phenomena beyond this study's immediate concerns. The aspect of this model relevant to multiplebody/split-consciousness cases may, when appropriately expanded and integrated with concepts from modern depth psychology, provide consciousness researchers with a base from which to reexplore the possible etiology of multiple personalities. The same expanded implementation may also, on a more limited scale, be useful in examining the phenomenon of spirit controls so integral to the psychodynamics of mediumship.

It is even possible that a study of various abnormal and mediumistic states of consciousness would uncover cases not just phenomeno- 
logically suggestive of but phenomenologically identical to the multiple-body/split-consciousness experiences cited in this article. The literature on psychedelic states of consciousness and a more detailed review of the neurological research spawned by Penfield's pioneer investigations might also be sources of relevant information. The personal multiple-body/split-consciousness descriptions of the parapsychologist and mystic Whiteman (1961) point to yet another possible source of testimonies, the vast literature of mysticism.

When the present study is scrutinized only within the context of the cases it covers and the application of hypercomplex geometry it invokes, we have an argument interesting in its suppositions but hardly overwhelming in its evidence. As noted, a neurological explanation derived from Penfield's (1975) research potentially offers an alternate hypothesis less extravagant in its assumptions and seemingly closer to scientific reasoning in its conclusions.

However, when this study is contemplated within a purview that encompasses $\mathrm{OBE} / \mathrm{NDE}$ states in general, an entirely different picture emerges. Connections begin to develop that organize sundry aspects of $\mathrm{OBE} / \mathrm{NDE}$ phenomenology into a single coherent framework. The shape of this complex phenomenological structure points, in my estimation, toward a higher-dimensional explanation for $\mathrm{OBE} /$ NDE states.

If descriptions of $\mathrm{OBE} / \mathrm{NDE}$ subjects seeming to correspond with spatial perception as it would occur in higher dimensions were entirely lacking, there' would be no good reason to explore the possibility that space possesses four dimensions, at least contingent on such observations. However, reports of OBE/NDE hyperspace perceptual effects have been collected. E.g., the recent research of Ring (1982) on the apparent precognitive aspects of panoramic memory recall during NDEs is highly compatible with a higher-space interpretation. Of these cases Ring remarked, "It is as though the individual sees something of the whole trajectory of his life, not just past events as some previous accounts (e.g., Moody, 1975; Noyes and Kletti, 1977) have implied" (p. 49). Ring presented the first systematically collected and well-documented evidence suggesting that the fourdimensional world of Einstein's special relativity is more than just an abstract mathematical entity.

Once again, this only becomes impressively evident when these seemingly precognitive experiences are contemplated within an $\mathrm{OBE} /$ NDE context that also includes the reported descriptions of circular and spherical vision (Green, 1968; Mitchell, 1981; Greene, 1983); seeing around corners and seeing three-dimensional objects from all 
sides at once (Moody, 1975; Osis, 1978; Greene, 1983); visual and bodily space distortions (Greene, 1983); and, as this study has attempted to illustrate, the multiple-body/split-consciousness effect.

\section{NOTES}

1. In this study all varieties of $O B E$ and related altered states (e.g., NDEs, which may or may not specifically include an OBE component) are assumed to possess equivalent phenomenological value.

2. The experiencer's ambiguous recounting of his NDE makes this perhaps the most difficult case in the study to interpret clearly. It is difficult to determine whether the subject actually intended to describe his experience in terms of a division in consciousness. His description of viewing his physical and OBE bodies as if from a third location, however, qualifies this experience as a member of this general class of OBE/NDE phenomenology.

3. The pronouncement "Not necessarily simultaneously" seems to suggest that this subject's experience included an element of time. However, the description that this shifting among various positions occurred within "no interval in time" seems to cancel the suggested sequence. The apparent contradiction in these words can be logically transcended if we assume that the experient was referring to time as a multidimensional phenomenon with spatial as well as temporal properties. A multilevel universe including a multiple number of spaces and times (Dunne's (1927) multidimensional infinite-regress model comes to mind) is compatible with such a view. Inasmuch as the third dimension may be conceived of as a successively apprehended cross section of fourdimensional space, so four-dimensional space may be regarded in like manner relative to five-dimensional space. Thus a four-dimensional observer, while recognizing certain spatial properties within phenomena viewed from "below" as temporal, would still experience a sense of sequence or time derived from what lies "above."

4. There is at least one significant difference between Penfield's "dual awareness" cases and the currently considered OBE/NDE 'split-consciousness sensations. Penfield's patients simultaneously encompassed perspectives remote in space and time while this study's OBE/NDE subjects experienced consciousness division in space only, with the exception of the panoramic-memory subject (from Noyes and Kletti, 1977) whose multiple-perspective sensations bridged both space and time. This last example may be viewed as a phenomenological link between Penfield's cases and 
the OBE/NDE accounts of the present study.

5. This line of thought is similar to an earlier speculation by Green who, commenting upon wide-angle/ceiling OBE perspectives, remarked:

In seeking for psychological factors which may determine these common ecsomatic positions, we should observe that the ceiling, and particularly the corner of the ceiling, is the vantage point from which one can survey the greatest area, without violating one's sense of the normal fitness of things by passing through the ceiling. The corner of the ceiling may also be the point within the room which is furthest removed from one's physical body $(1968$, p. 40$)$.

\section{REFERENCES}

Bragdon, C. Explorations into the Fourth Dimension. Lakemont, Georgia: CSA Press, 1972.

Broad, C.D. Lectures on Psychical Research. London: Routledge and Kegan Paul, 1962.

Clifford, W.K. The Common Sense of the Exact Sciences. New York: Dover, 1955.

Crookall, R. More Astral Projections. London: Aquarian Press, 1964a. Crookall, R. The Study and Practice of Astral Projection. London: Aquarian Press, 1964b.

Crookall, R. The Supreme Adventure. Cambridge, England: James Clark and Co., 1961.

Davies, P. Other Worlds. New York: Simon and Schuster, 1980. Dunne, J.W. An Experiment With Time. London: Faber and Faber, 1927.

Gallup, G., Jr. Adventures in Immortality. New York: McGraw-Hill, 1982.

Green, C. Out-of-Body Experiences. Oxford, England: Institute of Psychophysical Research, 1968.

Greene, F.G. A glimpse behind the life review. Theta, 1980, $8(2)$, 10-14.

Greene, F.G. The out-of-body experience, extrasomatic or intrasomatic phenomenon: a non-Euclidean/higher-space approach. Journal of Religion and Psychical Research, 1983, in press.

Gregory, S., and Thompson, L. Superclusters and voids in the distribution of galaxies. Scientific American, 1982, 246(3), 106-114. 
Helmholtz, H. v. On the origin and meaning of geometric axioms, In J. Newman (Ed.), The World of Mathematics. Vol. I. New York: Simon and Schuster, 1956.

Krishnan, V. Out-of-the-body vision. Parapsychology Review, 1982, 13(2), 21-22.

Mandelbrot, B. The Fractal Geometry of Nature. San Francisco: W.H. Freeman, 1982.

Mandelbrot, B. Fractals: Form, Chance and Dimension. San Francisco: W.H. Freeman, 1976.

Mitchell, J. Out-of-Body Experiences: A Handbook. Jefferson, N.C.: McFarland, 1982.

Moody, R. Life After Life. Atlanta: Mockingbird Press, 1975. Muldoon, S., and Carrington, H. The Phenomenon of Astral Projection. London: Rider, 1951.

Nagel, E. Space and geometry. In J.J. Smart (Ed.), Problems of Space and Time. New York: Macmillan, 1979.

Noyes R., and Kletti, R. Panoramic memory: a response to the threat of death. Omega, 1977, 8, 181-193.

Osis, K. Out-of-the-body research at the American Society for Psychical Research. In D.S. Rogo (Ed.), Mind Beyond the Body. New York: Penguin, 1978.

Penfield, W. The Mystery of the Mind. Princeton, N.J.: Princeton University Press, 1975.

Poincare, H. Science and Hypothesis. New York: Dover, 1952.

Ring, K. Life at Death. New York: Coward, McCann and Geoghegan, 1980.

Ring, K. Precognitive and prophetic visions in near-death experiences. Anabiosis, 1982, 2, 47-74.

Robertson, H.P. Geometry as a branch of physics. In J.J. Smart (Ed.), Problems of Space and Time. New York: Macmillan, 1979.

Rogo, D.S. Conceptual models. In D.S. Rogo (Ed.), Mind Beyond the Body. New York: Penguin, 1978a.

Rogo, D.S. Experiential aspects of out-of-body experiences. In D.S. Rogo (Ed.), Mind Beyond the Body. New York: Penguin, 1978b.

Rosen, S. A case of non-Euclidean visualization. Journal of Phenomenological Psychology, 1974, 5, 33-39.

Rosen, S. Paraphysical reality and the concept of dimension. Journal of Religion and Psychical Research, 1983, 6, 118-129.

Rosen, S. Toward a representation of the "irrepresentable." In J. White and S. Krippner (Eds.), Future Science. New York: Anchor, 1977. 
Rucker, R. Geometry, Relativity and the Fourth Dimension. New York: Dover, 1977.

Rucker, R. Infinity and the Mind. Cambridge, Mass.: Birhauser, 1982. Tyrrell, G.N.M. The Personality of Man. Harmondsworth, England: Penguin, 1947.

Whiteman, J.H.M. The Mystical Life. London: Faber and Faber, 1961.

Whiteman, J.H.M. The process of separation and return during experiences fully "out-of-the-body." In D.S. Rogo (Ed.), Mind Beyond the Body. New York: Penguin, 1978.

Requests for reprints to:

F. Gordon Greene

2322 Q Street, Apt. 21

Sacramento, CA 95816 